\title{
DIVERSIDADE GENÉTICA DE Anadenanthera peregrina (L.) Speg (Fabaceae) NO MUNICÍPIO DE GUAÇUÍ-ES
}

\author{
Kelmer Mozer Moro' \\ Lucimara Cruz de Souza ${ }^{2}$ \\ Adelson Lemes da Silva Júnior ${ }^{3}$ \\ Aléxia Gonçalves Pereira ${ }^{4}$ \\ Alessandra Abreu Rodrigues Vieira ${ }^{5}$ \\ Mariana Cruz De Souza ${ }^{6}$ \\ Fábio Demolinari de Miranda ${ }^{7}$
}

Resumo: A Floresta Atlântica vem sendo afetada por ações antrópicas ao longo no tempo e ainda continua sofrendo com essas ameaças. A fragmentação florestal ocasionada pelo desmatamento e o corte seletivo de espécies arbóreas contribui significativamente para a perda de diversidade genética nas populações naturais. Anadenanthera peregrina é uma espécie arbórea de grande porte e está sob efeito da fragmentação e corte seletivo. Análises genéticas a nível populacional são importantes para direcionar estratégias conservacionistas. Neste trabalho foi avaliada a diversidade genética de uma amostra populacional de trinta e cinco indivíduos de A. peregrina utilizando marcadores SSR. As análises permitiram dizer que a população não é endogâmica, provavelmente pelo fato da espécie ser predominantemente auto incompatível predominando a fecundação cruzada. A diversidade genética foi inferior a outros trabalhos com a mesma espécie, possivelmente pelo histórico da área. As árvores amostradas podem servir como fonte de sementes para produção de mudas destinadas ao reflorestamento.

Palavras-chave: Genética da conservação; Angico vermelho; Microssatélites; Diversidade genética; Desmatamento.

\footnotetext{
1 Graduação em Ciências Biológicas Bacharelado/Universidade Federal do Espírito Santo, Brasil. E-mail: kelmer.moro@gmail.com.

2 Pós-Graduação em Genética e Melhoramento/Universidade Federal do Espírito Santo, Brasil. E-mail: lucimaracruz15@hotmail.com.

3 Universidade Federal do Espírito Santo, Brasil. E-mail: adelsonlemes@yahoo.com.br.

${ }^{4}$ Universidade Federal do Espírito Santo, Brasil. E-mail: alexiagp@gmail.com.

5 Universidade Federal do Espírito Santo, Brasil. E-mail: abreuepires@gmail.com.

${ }^{6}$ Graduação em Agronomia/Universidade Federal do Espírito Santo, Brasil. E-mail: scruz.mariana@gmail.com.

7 Professor do Departamento de Biologia/Universidade Federal do Espírito Santo, Brasil. E-mail: fademolinari@yahoo.com.br.
} 